\title{
Potential Psychological Factors Associated with High Risk for Cannabis Abuse: Evidence from Multiple Logistic Regression
}

\section{Moez Bejaoui ${ }^{1}$ and Yousri Marzouki ${ }^{{ }^{*}}$}

${ }^{1}$ University of Tunis and Aix-Marseille Université, France

${ }^{2}$ Qatar University \& Aix-Marseille Université, France

\begin{abstract}
The aim of the present study was to provide a list of psychological variables likely to explain cannabis abuse among adolescents and young adults based on the following psychological risk factors: anxiety, depression, difficulty in describing feelings, difficulty in identifying feelings, and external oriented thought. The analysis was based on the multiple logistic regression technique; the step-wise procedure showed that only anxiety, depression, and difficulty in describing feelings were retained in the final model. Following this, additive versus interactive models under different assumptions between the three independent variables were also assessed. The key findings of this study are twofold: (a) anxiety was revealed to be the primary risk factor for cannabis abuse and (b) no interaction between the aforementioned factors proved to be significantly informative in explaining high risk cannabis abuse. Findings were discussed in the context of the current knowledge of the relationship between anxious and depressive symptoms and higher risk of substance abuse and dependence.
\end{abstract}

Keywords: Cannabis abuse; Anxiety; Depression; Alexithymia; Multiple logistic regression

\section{Introduction}

Given their capacity to actively operate on our central nervous system, psychoactive drugs are known to alter behavior, cognition, mood, and consciousness. The abuse of these substances can lead to psychological addiction and vice versa as a result of the stimulation of the brain's dopaminergic reward system. Among the illicit drugs, cannabis is one of the most used substances by teenagers and young adults. Cannabis use, abuse, and dependence are frequently seen in teenagers $[1,2]$ and young adults $[3,4]$. Cannabis is the most widely used illicit drug in Europe where consumption its use has significantly increased since 2011 .

According to the recent report of the "European Monitoring Center for Drugs and Drug Addiction" [5], France is among the top ranked countries in cannabis use. In addition, cannabis is considered the most consumed illegal substance among very young people (13-16 years). Indeed, $50 \%$ of 17 -year-old French teenagers have used cannabis at least once, and $7.3 \%$ are regular cannabis users. $42 \%$ among the $18-64$ year-old have already experienced cannabis use and $11 \%$ report having tried it at least once during the last year. Another interesting fact is that $2.2 \%$ are identified as users at high risk of abuse or dependence. Finally, $17 \%$ of the $18-25$ year-old people have smoked cannabis in the past month, $8 \%$ are regular users and $4 \%$ are users on a daily basis. Men were reported to be significantly more likely to use cannabis than women and this gap increases with higher levels of use.

Many studies have provided evidence for the increase in risk of physical disease associated with regular use of cannabis [6,7]. Recent studies have shown that the endocannabinoid system is highly involved in many neurobiological substrates underlying drug addiction [8]. More recently [1], showed that Delta(9)-tetra-hydrocannabinol, which is the psychoactive component in cannabis, can have a long-lasting effect on brain functions despite its minimal neurological variations. The damaging effects of a single exposure to cannabis on cognitive functions include: attention, memory, executive function deficits $[9,10]$ and auditory and visual information processing dysfunctions $[11,12]$.

Note: The DSM-IV differentiates between substance dependence and substance abuse. According to the DSM-IV-TR, substance abuse can be mainly diagnosed based on the following symptoms occurring at any time in the same 12-month period: 1 . recurrent substance use resulting in a failure to fulfill major role obligations at work, school, or home, 2. recurrent substance use in situations in which it is physically hazardous, 3. recurrent substance-related legal problems, 4 . continued substance use despite having persistent or recurrent social or interpersonal problems caused or exacerbated by the effects of the substance, 5 . the symptoms have never met the criteria for substance dependence for this class of substance [13].

The involvement of cannabis use in various psychiatric disorders has been established in many studies, including in schizophrenia [14,15], mood disorders [16-19], depression [20-22], anxiety [6] and behavioral disorders among young people. Brook [23,24] examined the association between psychosocial risk and protective factors and cannabis use disorders. They showed, among other things, that the increase in psychological symptoms (through personality attributes) is associated with an increased risk for cannabis use disorders.

\section{Cannabis abuse, anxiety, and depression}

The comorbidity between cannabis dependence/abuse and the DSM-III-R Axis I psychiatric diagnosis has been reported to be reliable. For example [25], found that $83 \%$ of their cannabis-dependent participants and $46 \%$ of their cannabis abusers met the DSM-III-R first psychiatric diagnosis axis.

*Corresponding author: Marzouki Y, Aix-Marseille Université - Pôle de Psychologie, 29 Avenue Robert Schuman, 13621 Aix-en-Provence, France, Tel: +33 413550 988; Fax: +33 488576 895; E-mail: yousri.marzouki@univ-amu.fr

Received: November 04, 2015; Accepted: November 06, 2015; Published: December 30, 2015

Citation: Bejaoui M, Marzouki Y (2015) Potential Psychological Factors Associated with High Risk for Cannabis Abuse: Evidence from Multiple Logistic Regression. Clin Exp Psychol 2: 107. doi:10.4172/2471-2701.10000107

Copyright: () 2015 Bejaoui M, et al. This is an open-access article distributed under the terms of the Creative Commons Attribution License, which permits unrestricted use, distribution, and reproduction in any medium, provided the original author and source are credited. 
Depression and anxiety have been reported to occur within addicted populations, which has led some researchers to acknowledge these factors as significant potential risk factors (comment 14) for addiction. Anxious and depressive disorders are common in adolescents and young adults [26] and are associated with a higher risk of substance use disorders [27] including cannabis use [28-30].

Hayatbakhsh [16] found that frequent cannabis use is linked to higher anxiety and depression in young adults, even in the absence of other illicit substance use. A follow-up longitudinal study [17] concluded that $22 \%$ of patients with regular Cannabis Use Disorder (CUD) had pre-existing anxiety disorders and $37 \%$ had pre-existing affective disorders. According to various studies, increasing cannabis use is associated with increasing levels of depression $[19,20]$. Moreover cannabis use has also been correlated to depressive disorders [31] anxiety symptoms $[6,25,32,33]$ and anxiety vulnerability $[34,35]$.

\section{Cannabis abuse and alexithymia}

Sifneos [36] coined the concept of alexithymia and defined it as an absence of words to describe emotions and also the incapacity to recognize emotions. Despite the fact that alexithymia was originally defined as a personality trait, it is currently considered as a state and a coping strategy. When facing stressful situations, alexithymia may play the role of a coping strategy in order to manage the anxiety generated by these situations. It is a state and a defensive style operating in daily life situations that overtake our adaptation capacities (e.g., a state of posttraumatic stress) suggested considering alexithymia as an adaptation of the cognitive system in the presence of constraining situations.

Contrary to the above mentioned disorders, alexithymia is not considered by the DSM to be mental disorder [13] even though it can be considered a risk factor and can be clinically associated with some somatic, neurological, psychiatric disorders as well as addiction [3741]. Moreover, alexithymia can even be detected among healthy people. In fact, according to [42], 21\% of healthy individuals showed high scores of alexithymia as opposed to $41 \%$ of drug addicted individuals and $63 \%$ of alcoholic individuals [43] provided an extensive empirical review of major studies that focused on abuse/dependence and several associated psychological factors. They found that 40 to $70 \%$ of substance abusers were also alexithymic $[25,44]$ reported that $30 \%$ of young cannabis abusers/dependent were alexithymic, based on the 20 -item Toronto Alexithymia Scale [TAS-20]. In a multimethod alexithymia assessment of 87 adolescents and young adults with a cannabis use disorder [45], found that $35.6 \%$ were alexithymic. Additionally, they used the Beck Depression Inventory (BDI) cutoff score to evaluate depressive symptoms: $2 \%$ of individuals presented severe depression, $22 \%$ moderate, and $36 \%$ mild depressive symptoms. Only these few studies had reported the prevalence of alexithymia among participants with high risk for cannabis abuse.

\section{The present study}

In the French context, the regular use of cannabis and more importantly its abuse (i.e., dependence) represent a major public health concern that includes:

-at the physical level: cancers of the lung and upper aerodigestive tract, diseases of the circulatory and respiratory system [46];

-at the mental level: anxiety disorders, panic attacks, depersonalization disorder, hallucinations, aggression and temporospatial disorientation, schizophrenia [47];

-at the social level: decrease of the academic and professional performance, and causes relationship, family and social problems [48];

-at forensic level, problems such as road traffic accidents [49] and delinquency.

All these health problems tend to increase as a function of the substance use [50].

The major focus in studying addictive behavior concerns drug and alcohol misuse. Despite a large amount of studies being focused on medical, epidemiological, forensic and also cognitive aspects that result from cannabis use, very few studies have examined the contribution of the psychological factors that lead to cannabis abuse or dependence. Moreover, when cannabis use disorders were studied in relation to psychiatric disorders, comorbidity with schizophrenia was found.

On the other hand, studies have already shown that addicted individuals significantly demonstrate increased depression and more anxiety symptoms relative to controls [51]. Furthermore, addicted individuals score high on standard alexithymia scales [52].

One common feature about the occurrence of psychological factors and addictive behavior in the mainstream of the studies cited above is that these factors are usually concomitant which can support the idea of comorbidity between psychological factors and addictive behavior. Accordingly, each of these psychological factors (anxiety, depression and alexithymia) must be tested within one regression model in order to individually evaluate their weights in estimating the high risk for cannabis abuse. Unlike previous studies that separately investigated the different roles of the aforementioned psychological factors of high risk for cannabis abuse, the present research used an experimental approach that examined their additive and interactive effects within a statistical regression framework.

\section{Method}

\section{Participants}

Initial sample of 268 students ( 44 males, mean age $=23$ years, $S D=$ 6.4; 224 females, mean age $=22$ years, $S D=5.2)$ from the University of Provence volunteered to participate in our study. They were presented with a series of self-report questionnaires including: CAGE-Alcohol (for alcohol dependence), CAST (for cannabis abuse) and Fagerström (for tobacco dependence). Only participants with cannabis abuse either exclusively or associated with alcohol were retained (Table 1). Based on their final scores on the three questionnaires, only 35 participants (men $=9$, mean age $=21, S D=1.26 ;$ women $=26$, mean age $=21, S D$ $=2.28$ ) were assigned to the experimental group ( 16 were exclusively participants with high risk for cannabis abuse) whereas 58 participants formed the control group (no abuse/dependence of any of the three substances) (men $=10$, mean age $=25, \mathrm{SD}=3.37$; women $=21$, mean age $=21, \mathrm{SD}=2.9$ ). All participants filled out a consent form prior to their participation.

Note: The other 175 participants were excluded from this study because they do not consume cannabis, however they can be tobacco or alcohol consumers. In addition, the 58 control subjects do not consume any of the following three substances: cannabis, alcohol and tobacco.

\section{Material}

Series of psychological screening tests was administrated for each participant in the following order:

The Cannabis Abuse Screening Test (CAST): This test was developed at the French Monitoring Center for Drugs and Drug Addiction (2107) 


\begin{tabular}{|l|l|l|l|l|l|l|}
\hline & & N & Age & Gender & $\begin{array}{l}\text { CAST score } \\
\text { weekly basis }\end{array}$ & $\begin{array}{l}\text { Cannabis amount on a Cannabis amount on a } \\
\text { daily basis }\end{array}$ \\
\hline $\begin{array}{l}\text { Addicted participants } \\
\text { (Experimental group) }\end{array}$ & $\begin{array}{l}\text { Cannabis only } \\
\begin{array}{l}\text { Cannabis } \\
+ \\
\text { Alcohol }\end{array}\end{array}$ & $n=16$ & 21 & 13 females & 15.56 & 10 times \\
\hline Control group & & $n=19$ & 21 & 13 females & 18.48 & 14 times \\
\hline
\end{tabular}

Table 1: Participants' characteristics.

and is a six-item screening test for cannabis abuse in general population. The CAST estimates the risk of abuse of cannabis in adolescence and early adulthood, and is used by the French Interdepartmental Mission for the fight against drugs and drug addiction (MILDT) [53], performed a test validation using a French sample of 1711 individuals aged from 14 to 22 in order to determine optimum thresholds for the CAST. Moreover, the CAST has showed a high internal consistency $(\alpha=.74)$ and a very high sensitivity and specificity (.93 and .81 respectively). The measure allows for two rating procedures: (a) a binary response rating and (b) a graduated rating (never, rarely, sometimes, quite often, and very often). In the first procedure, an overall score of 1 or 2 indicates a low level risk of abuse, a score of 3 indicates a moderate level and a score of 4 or more indicates a high level of risk abuse. The following two procedures were both used in the present study:

Hospital Anxiety and Depression Scale (HADS): The HADS is a self-report rating scale developed by [54] for anxiety and depression evaluation in hospital general medical outpatients. The HADS has been extensively used in primary care and in general population surveys. Fourteen items ( 7 for the anxiety subscale and 7 for the depression subscale) are presented in random order. Each item is scored on a fourpoint scale from 0 (not present) to 3 (considerable). Subscale scores are divided into 4 ranges: normal (0-7), mild (8-10), moderate (11-15) and severe (16-21). The French version of the HADS was validated by [55].

Toronto Alexithymia Scale (TAS-20): The TAS-20 is a 20 -item selfreport rating scale developed by [56]. The current version of TAS-20 has three subscales: i) difficulty describing feelings subscale (DDF, five items), difficulty identifying feelings subscale (DIF, seven items) and externally-oriented thinking subscale (EOT, eight items). Items are rated using a five-point Likert scale from 1 (strongly disagree) and 5 (strongly agree). The total alexithymia score is the sum of responses to all 20 items, while the score for each subscale is the sum of the responses to items for that subscale. The TAS-20 is based on a cutoff scoring: a score from 0 to 51 points indicates non-alexithymia, a score from 52 to 60 indicates possible alexithymia and a score from 61 to 100 points indicates alexithymia. French validation was performed by [57].

Note: According to a recent psychometric study on the French version of the CAST [58], used several indicators to identify the optimal scores mainly: the sensitivity measure that reflects the proportion of true positives (i.e., those screened positive with the CAST when having a clinical diagnosis) and the specificity indicates the proportion of true negatives (i.e., those with a negative screening result when having no diagnosis). In order to determine the best balance between sensitivity and specificity, they calculated the Youden index $\mathrm{Y}$ as an indicator of the ability of the CAST to discriminate between individuals with and without a diagnosis.

Cannabis abuse is the dependent variable and was treated as a binary outcome as follows: 0 indicates participants with no high risk for cannabis abuse, 1 indicates participants with high risk for cannabis abuse. The following five continuous independent variables were considered: Anxiety, Depression, difficulty describing feelings, difficulty identifying feelings and externally-oriented thinking.

\section{Analyses}

In presence of a binary outcome, the Generalized Linear Model is the alternative statistical technique to be applied given the absence of basic normal distribution requirements of the dependant variable [59]. Logistic regression is the appropriate method to use to explain a dichotomous outcome by continuous regressors. To do this, the multiple logistic regression technique was used. This technique has become a standard method in many recent clinical and epidemiological studies [60]. Additional analyses including: (a) regression diagnosis with stepwise procedure (b) additive versus multiplicative models comparisons and (c) odds ratios (ORs) to evaluate psychological risk factors associated with cannabis abuse.

\section{Results}

Table 2 gives a description of the standard distribution statistics for the five psychological risk factors for all participants. Figure 1 provided the distribution for each factor against groups (participants with high risk vs. control). Anxiety, depression, and difficulty identifying feelings showed the most segregation between abusers and control participants whereas externally-oriented thinking presented a significant overlap between the two groups. Difficulty describing feelings showed a big inter-subject variability, though limited only to the case of participants with high risk for cannabis abuse. For depression, results show that the average of participants with high risk of cannabis abuse seems to fall around 11 (mild to low moderate) while the mean for the participants with no high risk of cannabis abuse is in the normal range. A more interesting result appears for anxiety, where participants with high risk of cannabis abuse appears to have a bi-modal distribution with respect to anxiety, with the upper part of the distribution having scores in the mild to moderate range and the lower part of the distribution clearly in the normal range. All of the non-abusers are in the normal range.

\section{Multiple regression analysis}

A multiple logistic regression analysis was conducted on our data with cannabis abuse ( $0=$ control vs. $1=$ abusers $)$ as a binary outcome and anxiety, depression, difficulty describing feelings, difficulty identifying feelings and externally oriented thinking as five continuous regressors. Table 3 presents the estimated parameters of the model and the odds ratio for each factor. The results show that the only significant factor is anxiety $(p<.01)$ and depression $(p<.05)$, while difficulty-describing feelings was not significant $(p=.092)$.

For a one unit in the anxiety subscale, the log odds of being participants with high risk for cannabis abuse increases by 1.30 . According to the odds-ratio, obtained by exponentiating the regression coefficients, cannabis abuse is 3.7 times more likely when the person is anxious, 3.5 times more likely when the person is depressive and 1.3 times more likely when a person shows signs of difficulty describing feelings.

\section{Stepwise procedure and model selection}

Since not all factors showed a significant effect on the outcome, it 
Citation: Bejaoui M, Marzouki Y (2015) Potential Psychological Factors Associated with High Risk for Cannabis Abuse: Evidence from Multiple Logistic Regression. Clin Exp Psychol 2: 107. doi:10.4172/2471-2701.1000107

Page 4 of 7

\begin{tabular}{|c|c|c|c|c|c|}
\hline & Mean & sd & Min - Max & Skew & Kurtosis \\
\hline Anxiety & 8.16 & 3.61 & $1-19$ & 0.71 & 0.11 \\
\hline Depression & 3.84 & 3.72 & $0-14$ & 1.07 & -0.22 \\
\hline DDF & 12.05 & 4.58 & $5-25$ & 0.62 & -0.05 \\
\hline DIF & 15.77 & 6.24 & $7-32$ & 0.81 & -0.20 \\
\hline EOT & 15.65 & 3.69 & $8-26$ & 0.12 & -0.59 \\
\hline
\end{tabular}

Table 2: Descriptive statistics summary related to the five continuous predictors in the regression model.
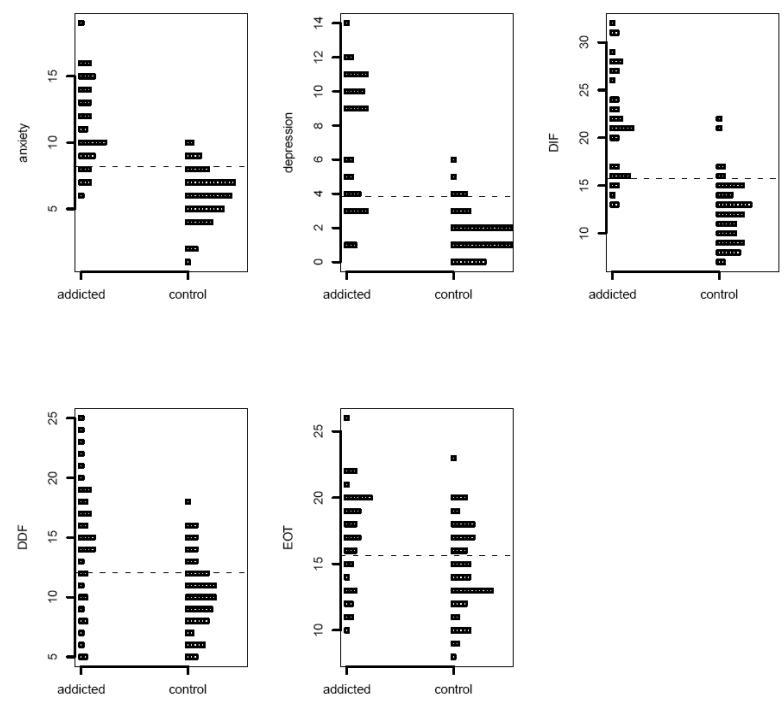

Figure 1: Strip chart graphic representing the discrete distributions of the five predictors in the initial model as a function of cannabis addiction (addicted vs. control). The dashed lines represent the means of the variables for all participants.

is possible to select, either by deletion or inclusion, the most relevant explanatory variables of cannabis abuse by conducting a stepwise technique based on the Akaike Information Criterion (AIC). The retained best model was reported in Table 4 . This model included only the three reliable factors: anxiety $(p<.005)$, depression $(p=.005)$ and difficulty describing feelings $(p<.05)$. According to the odds ratios of the final model, $54.3 \%$ of anxious individuals are likely to be individuals with high risk for cannabis abuse relative to $55.1 \%$ of depressive individuals and $21.8 \%$ of individuals with difficulty describing feelings. Figure 2 shows the curves of the regression effects for the three factors; it can be seen that difficulty describing feelings showed a less sigmoidal shape compared to anxiety and depression, which suggests that its statistical significance in the retained model is likely to be at some point mediated by anxiety and depression (Appendix 1).

\section{Additive vs. Interactive regression models comparison}

In order to assess a potential contributing effect of any interaction between the three retained factors, we compared in Table 5, all possible interaction models derived from the three variables against M1, the additive model reported in Table 4. None of the interaction terms in the four multiplicative models was significant $\left(p_{s}>1\right)$ and is indicated by higher AIC values compared to M1, which showed the lowest AIC and consequently is the more parsimonious model. This latter comparison is crucial to demonstrate that anxiety, depression and difficulty describing feelings do not interact between each other to explain high-risk cannabis abuse.

\begin{tabular}{|c|c|c|c|}
\hline Factor & $\boldsymbol{\beta}$ value & $\boldsymbol{P}$ value & Odds ratio \\
\hline Intercept & -22.5 & .002 & $1.7 \mathrm{e}-10$ \\
Anxiety & $1.26^{\star *}$ & .01 & 3.7 \\
Depression & $1.21^{*}$ & .02 & 3.5 \\
DDF & 0.26 & .09 & 1.3 \\
DIF & 0.10 & .62 & 1.1 \\
EOT & 0.25 & .20 & 1.3 \\
\hline
\end{tabular}

Table 3: Multiple logistic regression coefficients and odds ratios (ODs) for the initia additive model including five predictors.

\begin{tabular}{|c|c|c|c|}
\hline Factor & $\boldsymbol{\beta}$ value & $\boldsymbol{P}$ value & Odds ratio \\
\hline Intercept & -17.07 & 0.0002 & $3.8 \mathrm{e}-08$ \\
Anxiety & 1.19 & 0.0015 & 3.318125 \\
Depression & 1.23 & 0.0050 & 3.428422 \\
DDF & 0.28 & 0.0450 & 1.332158 \\
\hline
\end{tabular}

Table 4: Multiple logistic regression coefficients and odds ratios (ODs) for the best model after a stepwise procedure.

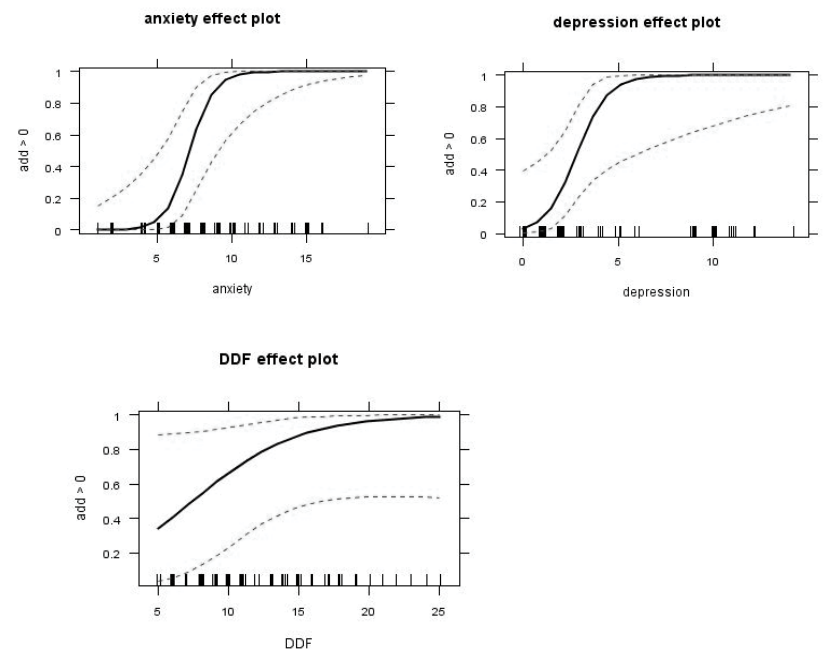

Figure 2: The graphical representation of the logistic regression effects curves with plus or minus confidence interval (dashed lines) for the three predictors in the retained model. Anxiety and depression in the upper panels and DDF in the lower panel. Note that sigmoidal shape is more obvious with anxiety and depression and less obvious with DDF.

\section{Discussion}

Using a multiple logistic regression model, five variables were tested to investigate cannabis abuse: anxiety, depression, difficulty in describing feelings, difficulty in identifying feelings and external oriented thought. The choice of these factors was based on the variables most frequently reported as overlapping in many studies about alcohol and drug abuse/dependence. Unlike those studies that were mainly descriptive, the present research provides an exploratory regressive model of cannabis abuse.

Our preliminary results are consistent with the $[25,45]$ studies that found $30 \%$ alexithymia among cannabis abusers and 36\% alexithymia among cannabis-dependent participants. In the present study, $36.1 \%$ of participants with high risk for cannabis abuse were revealed to be also alexithymic. Furthermore [45], observed that $58 \%$ of their alexithymic participants were depressed (mildly and moderately). Accordingly, $47 \%$ of the present study's participants were found to be depressed (mildly and moderately). According to the literature, despite using different depression assessment scales (Beck Depression Inventory in [45], these 


\begin{tabular}{|c|c|c|c|c|c|}
\hline Model expression & DF residual & $\begin{array}{l}\text { d e } v i \text { a } n c e \\
\text { residual }{ }^{\mathrm{a}}\end{array}$ & DF & Deviance & $\mathrm{AIC}^{\mathrm{b}}$ \\
\hline M1. addiction = anxiety + depression + DDF & 91 & 26.10 & & & 34.10 \\
\hline M2. addiction = anxiety + depression + DDF + (anxiety $x$ depression $)$ & 90 & 26.01 & 1 & 0.08767 & 36.01 \\
\hline M3. addiction = anxiety + depression + DDF + (anxiety $\times$ DDF $)$ & 90 & 25.01 & 0 & 1.00524 & 35.01 \\
\hline M4. addiction = anxiety + depression + DDF + (depression $x$ DDF $)$ & 90 & 25.62 & 0 & -0.61127 & 35.62 \\
\hline M5. addiction $=$ anxiety + depression + DDF $+($ anxiety $x$ depression $\times$ DDF $)$ & 87 & 24.72 & 3 & 0.90067 & 40.72 \\
\hline
\end{tabular}

Table 5: Model comparisons between the additive model, M1. and 4 multiplicative models (M2, M3, M4 \& M5) based on residual deviance parameter and AIC value as goodness of fit measures.

a Observations with a deviance residual in excess of two may indicate lack of fit.

${ }^{b}$ Akaike Information Criterion calculated by the following formula: $2 k-2 \ln (L)$ with $k$ being the number of parameters in the model and $L$ being the maximized log-likelihood of the estimated model.

proportions were about the same.

The present study showed that only anxiety, depression, and difficulty in describing feelings were retained in the final regression model. This is consistent with what has been argued by $[26,27]$ concerning the robust relationship between anxious and depressive symptoms and higher risk of substance abuse and dependence in adolescents and young adults. More important is that this relationship was also observed with heavy users of cannabis [28,25] speculated that the relationship between cannabis addiction and anxiety may be caused by another risk factor such as personality traits disorders. The present study went beyond [45] interpretation and we gave a broader account for risk factors. The relationship between depression, anxiety, and alexithymia is controversial: for some authors both anxiety and depression can be explained by alexithymia $[60,61]$ while for others alexithymia is explained by anxiety and depression [62,63]. However, depression, anxiety, and alexithymia can be also distinct constructs or separate dimensions reinforcing each other [64]. This statement is supported by the lack of fit of all the multiplicative models (including all the two-way and the three-way interaction terms) of interaction tested in this study, in comparison to the additive model that was retained. However, the regression model cannot further explain the direction of the causal relationship between cannabis abuse and the studied factors. In fact, cannabis use could reversely promote anxious and depressive symptoms as stated by some authors [6]. Anxiety was revealed to be a major factor of cannabis abuse in our study. This result is in line with previous findings that reported high levels of anxiety among cannabis users as a linear function of use, abuse, and dependence [28,65]. Finally, self-medication and cannabis use is another aspect worthy of mention to further explain the primary effect of anxiety in the regression model. Indeed [66], showed that individuals with high levels of anxiety tend to use cannabis in order to self-medicate their anxious symptoms. This contributing factor is likely to be observed within a normal population that attributes addictive behavior to a self-medication purpose [62]. Despite its explanatory nature, the present study provided a preliminary description of the most relevant psychological factors that may explain cannabis abuse. Follow-up studies will shed more light on other factors that can potentially predict cannabis abuse, such as coping mechanisms, quality of life, and well-being.

\section{Possible contribution of the research to health policy}

In France, heavy users (abuse and dependence) of cannabis are welcomed in health centers, support and addictology prevention programs. These centers have outpatient consultations in addiction or in general practice. The country has witnessed in the recent years a growing awareness of the implications for public health of the widespread and long-term consumption of this substance. This awareness has led to an increase in the number of care demands for cannabis-related problems. However, improving the governance of public policy in the fight against drugs and addictive behavior implies the need for scientifically validated data. The latter are useful to the development of public policies that are more effective in providing health professionals dealing with teenagers and young adults with critical cannabis use, with tools for prevention when they directly deal and, identifying and taking health and psychosocial therapy. Hence, the quantitative psychopathology of addictive behavior such as the approach presented in the current study has the potential to identify certain risk factors or psychological vulnerability towards cannabis abuse and dependence. The most identified risk factors refer to anxiety, depression and emotional disorders, including alexithymia that play the role of behavioral indicators of heavy addiction problems [26].

\section{Limits and perspectives}

One limitation of this study is the small sample size. Only 35 individuals who met the criteria of the CAST scale were selected from an initial sample of 268 participants. They were considered as individuals with high risk for cannabis abuse. A larger sample would allow comparisons between men vs. women and a more robust "generalization" of the obtained results. Indeed, gender can be a potential confounding factor and the unequal sex ratio in the present study stemmed from the fact that the chosen population was psychology students. In France, this population is largely female. Gender can be a detrimental variable, especially in relation with the description of emotions. Future studies must explore the role of gender in high risk for cannabis abuse.

Another limitation is the nature of the assessment tools. In France, the use of cannabis is illegal, so it is likely that part of the participants have downplayed or omitted their consumption and are therefore considered non-abusers. The self-report tools have the advantage of speed and ease to obtain data, but they have the disadvantage of somehow biasing the diagnosis due to the participants' subjective judgments such as their emotions and attitudes. One may ask, how an alexithymic person unable to express his/her own emotions can report responses related to his/her depressive or anxious states. This issue is paramount as long as alexithymia is assumed from a typological (or categorical) perspective.

However, in the present study all the measuring scales are based on participants' self-reports, including the HAD and the TAS-20 and alexithymia was considered from a dimensional perspective (in terms of continuity and severity). The concept of alexithymia has been operationalized with many dimensions and the TAS-20 is among the most used self-report tools. Nevertheless, it seems imperative to combine for future studies self-assessment methods with observers' reports also referred to as hetero-assessment (e.g., by using Mini International Neuropsychiatric Interview). Accordingly, by replicating this study in health care institutions with in-patients and out-patients based on a psychiatric diagnosis where anxiety and depression would be treated as typological variables, data from patients and participants 
Citation: Bejaoui M, Marzouki Y (2015) Potential Psychological Factors Associated with High Risk for Cannabis Abuse: Evidence from Multiple Logistic Regression. Clin Exp Psychol 2: 107. doi:10.4172/2471-2701.1000107

Page 6 of 7

of a general population can be directly compared.

\section{References}

1. Malone DT, Hill MN, Rubino T (2010). Adolescent cannabis use and psychosis: epidemiology and neurodevelopmental models. British Journal of Pharmacology 160: 511-522.

2. Perkonigg A, Lieb R, Höfler M, Schuster P, Sonntag H, et al. (1999) Patterns of cannabis use, abuse and dependence over time: Incidence, progression and stability in a sample of 1228 adolescents. Addiction 94: 1663-1678.

3. Ogborne AC, Smart RG (2000) Cannabis users in the general Canadian population. Substance Use and Misuse 35: 301-311.

4. Webb E, Ashton CH, Kelly P, Kamali F (1996) Alcohol and drug use in UK university students. The Lancet 348: 922-925.

5. Observatoire Français des Drogues et Toxicomanies (OFDT) Principales évolutions du phénomène des drogues et des toxicomanies en France, 2014. http://www.ofdt.fr/publications/collections/rapports/rapports-nationaux/.

6. Bonn-Miller MO, Zvolensky MJ, Leen-Feldner EW, Feldner MT, Yartz AR (2005) Marijuana use among daily tobacco smokers: Relationship to anxiety-related factors. Journal of Psychopathology and Behavioral Assessment 27: 279-289.

7. Kalant $H$ (2004) Adverse effects of cannabis on health: an update of the literature since 1996. Progress in Neuro-Psychopharmacology \& Biological Psychiatry. 28: 849-863.

8. Maldonado R, Valverde O, Berrendero F (2006) Involvment of the endocannabinoid system in drug addiction. Trends in neurosciences 29: 225-232.

9. Bolla KI, Brown K, Eldreth D, Tate K, Cadet JL (2002) Dose-related neurocognitive effects of marijuana use. Neurology 59: 1337-1343.

10. Solowij N, Stephens RS, Roffman RA, Kadden T, Miller R Christiansen M, et al. (2002) Cognitive functioning of long-term heavy cannabis users seeking treatment. The Journal of the American Medical Association 287: 1123-1131.

11. Kempel P, Lampe K, Parnefjord R, Hennig J, Kunert HJ (2003) Auditory-evoked potentials and selective attention: different ways of information processing in cannabis users and controls. Neuropsychobiology 48: 95-101.

12. Semple DM, Ramsden F, McIntosh AM (2003) Reduced binocular depth inversion in regular cannabis users. Pharmacology Biochemistry and Behavior 75: 789-793.

13. American Psychiatric Association (2000) Diagnostic and statistical manual of mental disorders. (DSM-IV-TR) Washington: APA.

14. Foti DJ, Kotov R, Guey LT, Bromet EJ (2010) Cannabis use and the course of schizophrenia: 10-year follow-up after first hospitalization. American Journal of Psychiatry 167: 987-993.

15. McGrath J, Welham, J, Scott J, Varghese D, Degenhardt L, et al. (2010) Association between cannabis use and psychosis-related outcomes using sibling pair analysis in a cohort of young adults. Archives of General Psychiatry 67: $440-447$

16. Hayatbakhsh MR, Najman JM, Jamrozik K, Mamun AA, Alati R, et al. (2107) Cannabis and anxiety and depression in young adults: a large prospective study. The American Academy of Child and Adolescent Psychiatry 46: 408-417.

17. Höfler M, Lieb R, Perkonigg A, Schuster P, Sonntag H, et al. (1999). (1999). Covariates of cannabis use progression in a representative population sample of adolescents: a prospective examination of vulnerability and risk factors. Addiction 94: 1679-1694.

18. Regier DA, Farmer ME, Rae DS, Locke BZ, Keith SJ, et al. (1990) Comorbidity of mental disorders with alcohol and other drug abuse. Results from the Epidemiologic Catchment Area (ECA) study. Journal of the American Medical Association 264: 2511-2518.

19. Rey JM, Sawyer MG, Raphael B, Patton GC, Lynskey M (2002) Mental health of teenagers who use cannabis. Results of an Australian survey. British Journal of Psychiatry 180: 216-221.

20. Arendt M, Munk-Jørgensen P (2004) Heavy cannabis users seeking treatmentprevalence of psychiatric disorders. Social Psychiatry and Psychiatric Epidemiology 39: 97-105.

21. Bovasso GB (2001) Cannabis abuse as a risk factor for depressive symptoms. American Journal of Psychiatry 158: 2033-2037.
22. Brook DW, Brook JS, Zhang C, Cohen P, Whiteman M (2002) Drug use and the risk of major depressive disorder, alcohol dependence, and substance use disorders. Archives of General Psychiatry 59: 1039-1044.

23. Brook JS, Lee JY, Finch SJ, Koppel J, Brook DW (2011) Psychosocial factors related to cannabis use disorders. Substance abuse 32: 242-251.

24. Brook JS, Lee JY, Brown EN, Finch SJ, Brook DW (2011) Developmental trajectories of marijuana use from adolescence $t$ adulthood: Personality and social role outcomes. Psychological Reports 108: 339-357.

25. Troisi A, Pasini A, Saracco M, Spalletta G (1998) Psychiatric symptoms in male cannabis users not using other illicit drugs. Addiction 93: 487-492.

26. Woodward LJ, Fergusson DM (2001) Life course outcomes of young people with anxiety disorders in adolescence. Journal of the American Academy of Child and Adolescent Psychiatry 40: 1086-1093.

27. Aarons GA, Brown SA, Hough RL, Garland AF, Wood PA (2001) Prevalence of adolescent substance use disorders across five sectors of care. Journal of the American Academy of Child and Adolescent Psychiatry 40: 419-426.

28. Cheung JT, Mann RE, lalomiteanu A, Stoduto G, Chan V, et al. (2010) Anxiety and mood disorders and cannabis use. The American Journal of Drug and Alcohol Abuse 36: 118-122.

29. Compton WM, Cottler LB, Phelps DL, Ben Abdallah A, Spitznagel EL (2000) Psychiatric disorders among drug dependent subjects: are they primary or secondary? American Journal on Addictions 9 : 126-134.

30. McGee R, Williams S, Poulton R, Moffitt T (2000) A longitudinal study of cannabis use and mental health from adolescence to early adulthood. Addiction 95: 491-503.

31. Degenhardt L, Hall W, Lynskey M (2003) The relationship between cannabis use, depression and anxiety among Australian adults: findings from the National Survey of Mental Health and Well-Being. Social Psychiatry and Psychiatric Epidemiology 36: 219-227.

32. Fergusson DM, Horwood LJ (1997) Early onset cannabis use and psychosocial adjustment in young adults. Addiction 92: 279-296.

33. Zvolensky MJ, Bernstein A, Marshall EC, Feldner MT (2006) Panic attacks panic disorder, and agoraphobia: Associations with substance use, abuse, and dependence. Current Psychiatry Reports 8: 279-285.

34. Dannon P N, Lowengrub K, Amiaz R, Grunhaus L, Kotler M (2004) Comorbid cannabis use and panic disorder: Short term and long term follow-up study. Human Psychopharmacology 19: 97-101.

35. Tournier M, Sorbara F, Gindre C, Swendsen JD, Verdoux H (2003) Cannabis use and anxiety in daily life: A naturalistic investigation in a non-clinical population. Psychiatry Research 118: 1-8.

36. Sifneos PE (1973) The prevalence of "alexithymic" characteristics in psychosomatic patients. Psychotherapy Psychosomatics 22: 255-262.

37. Corcos M, Speranza M (2003) Psychopathologie de l'alexithymie. Paris: Dunod

38. Keller DS, Caroll KM, Nich C, Rounsaville B J (1995) Alexithymia in cocaïne abusers. The American Journal of Addiction 4: 234-244.

39. Haviland MG, Hendryx M, Shaw DG, Henry JP (1994) Alexithymia in women and men hospitalized for psychoactive substance dependence. Comprehensive Psychiatry 35: 124-128.

40. Rybakowski J, Ziolkowski M, Zasadzka T, Brzezinski R (1988) High prevalence of alexithymia in male with alcohol dependence, Drug and Alcohol Dependence 21: 133-136.

41. Taylor GJ, Bagby RM, Parker JDA (1997) Disorders of affect regulation. Cambridge: Cambridge University Press.

42. Guilbaud O, Loas G, Corcos M, Speranza M, Stephan Ph, et al. (2002) L'alexithymie dans les conduites de dépendance et chez le sujet sain : valeur en population françaiseet francophone. Annales MédicoPsychologiques 160: $77-85$

43. Farges F, Farges (2002) Alexithymie et substances psychoactives : revue critique de la littérature. Psychotropes 8: 47-74.

44. Thorberg FA, Lyvers M (2006) Negative Mood Regulation (NMR) expectancies, mood, and affect intensity among clients in substance disorder treatment facilities. Addictive Behaviors 31: 811-820.

45. Dorard G, Berthoz S, Haviland MG, Phan O, Corcos M, et al. (2008) Multimethod 
Citation: Bejaoui M, Marzouki Y (2015) Potential Psychological Factors Associated with High Risk for Cannabis Abuse: Evidence from Multiple Logistic Regression. Clin Exp Psychol 2: 107. doi:10.4172/2471-2701.1000107

Page 7 of 7

alexithymia assessment in adolescents and young adults with a cannabis use disorder. Comprehensive Psychiatry 49: 585-592.

46. Sasco A., "Cannabis et risques somatiques " dans Cannabis, données essentielles. Saint-Denis, OFDT, 2006, pp.90-96.

47. Brisacier A.C., « Morbidité et mortalité liées aux drogues illicites », dans Drogues et addictions, données essentielles Saint-Denis, OFDT, 2013, pp. 105-112.

48. Bello P.-Y., et al. Les usagers fréquents de cannabis, éléments descriptifs, France, 2004Bulletin Epidémiologique Hebdomadaire, n²0, 2005, pp. 89-91.

49. Groupe SAM, et al. Stupéfiants et accidents mortels de la circulation routière (projet SAM). Synthèse des principaux résultats. Saint-Denis, OFDT, 2005, 39 p.

50. Crowleyn TJ, MacDonald MJ, Whitmore EA, Mikulich SK (1998) Cannabis dependence, withdrawal, and reinforcing effects among adolescents with conduct symptoms and substance use disorders. Drug Alcohol Dependency 50: 27-37.

51. Zeitlin SB, McNally RJ, Cassiday KL (1993) Alexithymia in victims of sexual assault: an effect of repeated traumatization? American Journal of Psychiatry 150: 661-666.

52. Taylor GJ, Bagby RM, Parker JDA (1992) The revised Toronto Alexithymia Scale: Some reliability, validity and normative data. Psychotherapy psychosomatics 57: $34-41$

53. Legleye S, Karila L, Beck F, Reynaud M (2107) Validation of the CAST, a general population Cannabis Abuse Screening Test. Journal of Substance Use 12: 233-242.

54. Zigmond AS Snaith RP (1983) The hospital anxiety and depression scale. Acta Psychiatrica Scandinavia 67: 361-370.

55. Lépine JP, Godchau M, Brun P, Lempérière T (1985) Evaluation de l'anxiété et de la dépression chez des patients hospitalisés dans un service de médecine interne. Annales MédicoPsychologiques $143: 175-189$

56. Bagby RM, Taylor GJ, Parker JDA (1994) The twenty-item Toronto alexithymia scale- II. Convergent, discriminant, and concurrent validity. Journal of Psychosomatic Research 38: 33-40.

57. Loas G, Fremaux D, Marchand MP, Chaperot C, Dardennes R (1993) L'alexithymie chez le sujets sain: validation de l'échelle d'alexithymie de Toronto (TAS) dans une population « tout venant » de 144 sujets, application au calcul de la prévalence. Annales MédicoPsychologiques 151:660-663.

58. Legleye S, Piontek D, Kraus $L$ (2011) Psychometric properties of the Cannabis Abuse Screening Test (CAST) in a French sample of adolescents. Drug and Alcohol Dependence 113: 229-235

59. Faraway JJ (2009) Extending the linear model with R: generalized linear, mixed effects and nonparametric regression models. Chapman \& Hall/CRC: Boca Raton.

60. Schneider JM, Fujii ML, Lamp CL, Lönnerdal B, Dewey KG, et al. (2008) The use of multiple logistic regression to identify risk factors associated with anemia and iron deficiency in a convenience sample of 12-36-mo-old children from low-income families. The American Journal of Clinical Nutrition 87: 614-620.

61. Loas G, Otmani O, Fremaux D, Lecercle C, Duflot M, et al. (1997) Is alexithymia a negative factor for maintaining abstinence? A follow up study. Comprehensive Psychiatry 38: 296-299.

62. Farges F, Corcos M, Speranza M, Loas G, Perez-Diaz F, et al. (2004) Alexithymie et toxicomanie : lien avec la dépression. Encephale 30: 201-211.

63. Honkalampi K, Hintikka J, Saarinen P, Lehtonen J et al. (2000) Is alexithymia a permanent feature in depressed outpatients? Results from a 6-month follow-up study. Psychotherapy and Psychosomatics. 69: 303-308.

64. Marchesi C, Brusamonti E, Maggini C (2000) Are alexithymia, depression, and anxiety distinct constructs in affective disorders? Journal of Psychosomatic Research 49: 43-49.

65. Regier DA, Rae DS, Narrow WE, Kaelber CT, Schatzberg AF (1998) Prevalence of anxiety disorders and their comorbidity with mood and addictive disorders. British Journal of Psychiatry 173: 24-28.

66. Stewart SH, Karp J, Pihl RO, Peterson RA (1997) Anxiety sensitivity and selfreported reasons for drug use. Journal of Substance Abuse 9: 223-240. 